\title{
Exploração de Paralelismo em Ambiente de Memória Distribuída e Híbrida para Simulação de CFD Aplicada
}

\author{
Mateus Specht ${ }^{1}$, Leonardo Bidese de Pinho ${ }^{1}$, Naylor Bastiani Perez ${ }^{2}$ \\ ${ }^{1}$ Universidade Federal do Pampa (Unipampa) - Campus Bagé \\ Bagé - RS \\ ${ }^{2}$ Empresa Brasileira de Pesquisa Agropecuária (Embrapa) - Unidade Pecuária Sul \\ Bagé - RS \\ mateus05specht@gmail.br, leonardopinho@unipampa.edu.br, \\ naylor.perez@embrapa.br
}

\begin{abstract}
Resumo. O presente trabalho explora uma aplicação de fluidodinâmica computacional para simular um aplicador de herbicida para controle de ervas daninhas em pastagens. O tempo de execução do processamento em arquiteturas computacionais de memória distribuída e híbrida foram comparados para identificar a capacidade de exploração do potencial de paralelismo do sistema.
\end{abstract}

\section{Introdução}

O aplicador de herbicida Campo Limpo possui como característica de trabalho a distribuição de calda de agroquímico por um elemento poroso. O fluxo da calda dentro do elemento aplicador é conduzido através de tubulações e as dimensões de construção influenciam o escoamento do implemento agrícola. As ferramentas de fluidodinâmica computacional (Computacional Fluid Dynamics - CFD) auxiliam na predição do comportamento de um fluido e a exigência computacional do sistema pode demandar o uso de técnicas de paralelismo para viabilizar sua execução [Versteeg and Malalasekera 2007]. O software Open Source Fields Operating and Manipulating (OpenFOAM) é um pacote de softwares desenvolvido em bibliotecas utilizando $\mathrm{C}++$, que foi escolhido para aplicação nesta pesquisa, entre outros softwares, em função da capacidade de exploração de recursos de paralelismo, possuir código fonte aberto e ampla capacidade de adaptação aos sistemas mais específicos [OpenCFD 2019]. Neste trabalho é apresentada uma abordagem voltada para avaliação do desempenho de diferentes ambientes computacionais (série e paralelo) para um estudo de caso aplicado de CFD.

\section{Metodologia}

A execução da aplicação CFD foi analisada a partir de aspectos voltados ao tempo de execução das ferramentas com arquiteturas em série e em paralelo com memória distribuída e híbrida. Os ambientes possuíam computadores com processador Intel Core i5-8400 CPU @ 2.80GHz 6 núcleos e 8 Gb de de RAM. Dois ambientes paralelos foram comparados com uso de diferente número de núcleos internos em cada nó, o primeiro ambiente foi concebido com dezesseis computadores com um deles centralizando a distribuição das tarefas e executando os processos ao mesmo tempo e um segundo cenário com dezessete computadores com um deles utilizando $32 \mathrm{~Gb}$ de RAM dedicado somente para gerencias a distribuição das tarefas. 


\section{Resultados de Estudo de Caso}

O tempo do processamento em série do estudo de caso da aplicação CFD foi utilizado para balizar o referencial temporal para o problema e utilizá-lo no comparativo com os demais ambientes. O tempo da execução em série está representado na Figura 1 por "Série" e a nomenclatura "1x1" faz alusão a um computador com um processador disponível por computador, assim como "16x2" indica o uso de dezesseis computadores e dois processadores disponíveis por computador. Os ambientes de processamento com memória distribuída estão representados como "Distribuída" e os com configuração híbrida como "Híbrida".

O menor tempo de execução foi identificado para o cenário "Híbrida 17x2" com uso dezesseis computadores com dois processadores disponíveis em cada nó e, posteriormente, o tempo para o cenário distribuído puramente com divisão em 16 computadores ("Distribuída 16x1"). A comparação entre os cenários "Distribuída 17x1" e o "Distribuída 17x2" indica um ganho da velocidade de execução, por outro lado os cenários "Híbrida 16x2" e "Híbrida 16x2" não mantiveram o mesmo comportamento de desempenho. Neste contexto existem indícios que o tempo de comunicação entre os diferentes nós pode limitar a eficiência do sistema, ao passo que um computador dedicado para gerenciar a execução da aplicação em paralelo pode melhorar o desempenho em arquiteturas híbridas [Council 2010].

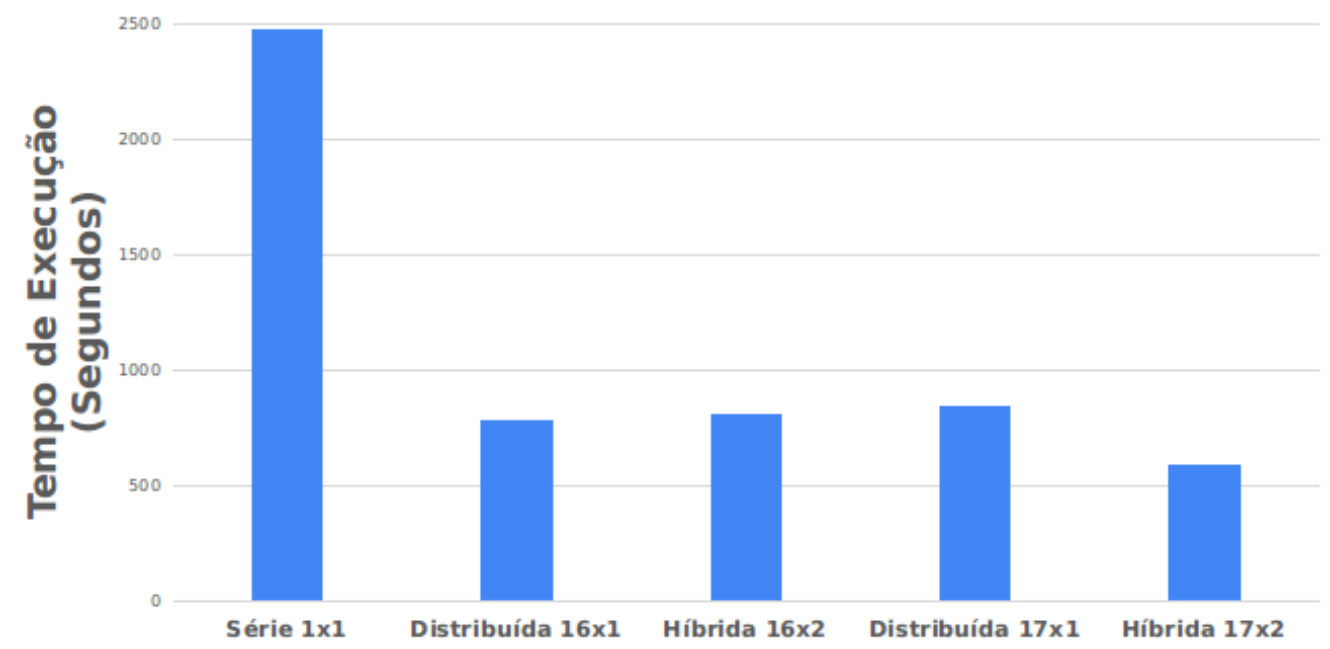

Figura 1. Avaliação de desempenho dos diferentes ambientes computacionais

\section{Referências}

Council, H. A. (2010). Openfoam performance benchmark and profiling. Disponível em: http://www. hpcadvisorycouncil. com/pdf/OpenFOAM_Analysis_and_.

OpenCFD (2019). User guide. In The OpenFOAM Foundation. OpenFOAM $®$ - Official home of The Open Source Computational Fluid Dynamics (CFD) Toolbox.

Versteeg, H. K. and Malalasekera, W. (2007). An introduction to computational fluid dynamics: the finite volume method. Pearson education, 3rd edition. 